\title{
2nd Russian Conference with International Participation "Hardware and Software of Control, Surveillance, and Measurement Systems" (CSM-10) (Moscow, ICS RAS, October 18-20, 2010)
}

DOI: $10.1134 /$ S0005117910070209

The goal of the conference is exchanging information on the results of modern studies and developments in hardware and software of control, surveillance, and measurement (CSM) systems. Finding prospective research directions and hardware and software developments aimed to increase efficiency, competitive power, and security of CSM systems.

\section{TOPICS OF THE CONFERENCE}

(1) Theory, research and design methods, and experience of applying technical means (from sensors to executing mechanisms) based on various physical and hardware design principles.

(2) Theory, algorithms, and software for CSM systems.

(3) Analyzing the current state, trends, and prospectives of CSM systems development.

(4) Discrete event models in CSM systems, including network-centric, logical, based on fuzzy logic, Petri nets etc.

(5) Creating CSM systems based on new technologies (micro- and nano-electromechanic and optoelectromechanic systems, biomicrosystems, wireless communication etc.).

(6) Computerized and physical modeling of hardware and software units of CSM systems.

(7) Multiprocessor and multicomputer systems as CSM system hardware, their structure, reliability, diagnostics.

(8) Theoretical and applied aspects of augmenting and estimating the quality of CSM system units (precision, efficiency, reliability, fail-safety, liveliness, diagnozability, intellectuality etc.), metrologic support for design and applications of CSM systems, their testing and certification.

(9) Design methods for hardware and software of CSM systems for working under extreme conditions and specific applications (nuclear energy, defense, space travel, transport, medicine, mining, environment etc.).

(10) Design and development of hardware and software for embedded, network, problem-oriented CSM systems.

(11) Problems of education in CSM systems.

Organizers: Trapeznikov Institute of Control Sciences of the RAS together with Department of Power Industry, Machine Industry, Mechanics and Control Processes of the RAS and the Scientific Council of the RAS on Control and Automation.

Submission rules for the conference and other information can be found at the conference web site, http://cmm.ipu.ru

Organizing committee address: 117997, Russia, Moscow, Profsoyuznaya ul., 65. Trapeznikov Institute of Control Sciences of the RAS, Moscow. Organizing Committee of the $2^{\text {nd }}$ CSM-10 conference. Phone: (495) 334-93-70, (495) 334-93-61. Fax: (495) 334-93-61.

Chair: Ambartsumyan Aleksandr Artem'evich, Sc.D.

Academic Secretary: Branishtov Sergei Aleksandrovich, Ph.D. 